BMJ Surgery, Interventions, \& Health Technologies

\section{Postmarket surveillance of high-risk medical devices needs transparent, comprehensive and independent registries}

Alan G Fraser (D)
To cite: Fraser AG. Postmarket surveillance of high-risk medical devices needs transparent, comprehensive and independent registries. BMJ Surg Interv Health Technologies 2020;2:e000065. doi:10.1136/ bmjsit-2020-000065

Received 02 September 2020 Accepted 14 September 2020

\section{Linked}

http://dx.doi.org/10.1136/ bmjsit-2020-000039

- http://dx.doi.org/10.1136/ bmjsit-2020-000067

Check for updates

(C) Author(s) (or their employer(s)) 2020. Re-use permitted under CC BY-NC. No commercial re-use. See rights and permissions. Published by BMJ.

Department of Cardiology, University Hospital of Wales, Cardiff, UK

Correspondence to Professor Alan G Fraser; FraserAG@cardiff.ac.uk
The judgement by Chalmers, the progenitor of the Cochrane Collaboration, that underreporting of research is scientific misconduct ${ }^{1}$ may appear harsh, but there are strong ethical arguments why clinical studies should be reported fully-so that unnecessary duplication of research with risks can be avoided and that insecure results can be replicated. Critical readers should be able to understand the data and assess the validity of any conclusions. The Declaration of Helsinki reminds us (at Article 36) that 'Researchers ... are accountable for the completeness and accuracy of their reports'.2

Requirements for reporting secondary research may be less strong but the methods of any study should still be described in sufficient detail to allow others to reproduce it. That has been reinforced by simulationspecific extensions to the Strengthening the Reporting of Observational Studies in Epidemiology recommendations for reporting observational research ${ }^{3}$ and by the Consolidated Health Economic Evaluation Reporting Standards guidance on reporting economic evaluations in healthcare. ${ }^{4}$ Aspects of both statements are relevant to the paper by Cronenwett $e t a \tilde{l}$ in this issue of BMJ Surgery, Interventions, $\mathcal{E}$ Health Technologies.

The authors present the costs of using the Vascular Quality Initiative (VQI), a registry maintained by the Society for Vascular Surgery in the USA, to undertake investigations of medical devices that were mandated by the US Food and Drug Administration (FDA). They compare them against the costs which they estimated would have been incurred if the manufacturers had instead organised their own studies. Actual and predicted costs were evaluated for six premarket investigations or postmarket surveillance studies that monitored high-risk devices used either for endovascular aortic repair (EVAR) or for peripheral angioplasty. The manuscript does not name the particular devices or disclose the requirements specified by the FDA, in part because of sensitivities of the manufacturers, nor does it break down the particular costs that were incurred by the VQI registry. The hypothetical ('counterfactual') costs were estimated using a published $\operatorname{model}^{6}$ but only the resulting total sums are reported. These omissions, which were self-imposed by the investigators, mean that readers are asked to take the results on trust. That limits the generalisability of their findings.

Frustrations about incomplete disclosure of data concerning postmarket surveillance of high-risk medical devices extend to the European Union (EU) where achieving transparency is hampered by the delegation of regulatory assessments to notified bodies, which as independent commercial organisations are not bound by EU legislation on freedom of access to information. The new EU Medical Device Regulation that will be implemented from 2021 continues to protect the privacy of information submitted by manufacturers. ${ }^{7}$ It is ironic that medical audit databases now place the clinical outcomes of individual surgeons in the public domain while data about the individual devices that they have used or implanted may be inaccessible. Until September 2016, specific device identities were not recorded by the $\mathrm{VQI}^{8}$ but now there should be no reticence about open disclosure and comparisons between competing devices or about the costs of maintaining registries.

An important issue in the use of registry data for regulatory purposes is its 
completeness. The International Medical Device Regulators Forum has recommended that a medical device registry should have a case ascertainment of at least $95 \%$, if it is to be accepted as providing high-quality data that are sufficiently robust to inform regulatory decisions. ${ }^{9}$ For registries that can be used to evaluate medicines, $100 \%$ inclusion rates are advised. ${ }^{10}$ In the six reported studies, all eligible patients in the participating hospitals were included and data capture was complete, but centres were selected and the studies enrolled an average of 169 patients $^{5}$ which is too few to assure safety. Earlier reports from the VQI registry stated that it included $82 \%$ of eligible patients who had had EVAR ${ }^{11}$ and that it captured a different profile of patients with peripheral arterial disease from alternative databases. ${ }^{12}$ Comprehensive recruitment might be attained by stipulating that entering data in a registry is a condition for institutional reimbursement.

The largest component of the actual costs of the registry studies was the charge per patient to manufacturers for access to the VQI data. ${ }^{5}$ The investigators have stated that this charge to industry is market driven, based on value and not relatable to specific costs. It includes payments to participating centres for entering additional data, and to the subcontractor responsible for monitoring data. The counterfactual estimates include overhead costs and per patient payments to centres. The net costs are given as two percentages, using alternate denominators-the difference between actual and estimated cost, over the estimated cost, as the 'cost-saving percentage'; and the estimated over the actual cost, as the 'return on investment'. Both figures are persuasive but their details are specific to the context of conducting a study in the USA. The focus was about saving costs and time, but what matters more is which method is more clinically effective-giving better quality, more comprehensive and more reliable data. ${ }^{13}$

There are increasing pressures on regulators worldwide to develop systems that can give accelerated access for patients and physicians to new high-risk medical devices. Such schemes increase the risks of unexpected complications, however, so they can be considered only if they are balanced by more postmarket evidence generation. The risks that are inherent in conditional approvals (or coverage with evidence development) should be shared by patients from all regulatory jurisdictions where a device will be available. Their data should be pooled through international collaborations of networks of registries, to enable the earliest possible detection of any safety signals. ${ }^{14}$

The benefits that can accrue from comprehensive registries are best exemplified by Sweden, which has 120 National Quality Registries integrated within its healthcare system. Data are collected routinely through the electronic health record and linked with other national databases. Funding is provided by the Swedish Association of Local Authorities and Regions. The Swedeheart registries on high-risk cardiovascular devices have been used as the platform to develop randomised registry trials. ${ }^{15}$ These may provide more valuable data to regulators more cost efficiently than reported by the VQI investigators, with capture of real-world experience and ready access to control populations.

The conclusion of Cronenwett et al-that it is more cost-effective to collect postmarket data about a highrisk medical device by using an existing registry run by a professional association than by initiating an industry-led study-is a welcome confirmation of the wisdom of current trends, at least if results are fully and promptly reported. Their study reinforces the need for manufacturers of all high-risk devices now to collaborate with academic bodies to support their registries and ensure their long-term sustainability.

Contributors AF wrote this himself without assistance.

Funding The authors have not declared a specific grant for this research from any funding agency in the public, commercial or not-for-profit sectors.

Competing interests None declared.

Patient consent for publication Not required.

Provenance and peer review Commissioned; internally peer reviewed.

Open access This is an open access article distributed in accordance with the Creative Commons Attribution Non Commercial (CC BY-NC 4.0) license, which permits others to distribute, remix, adapt, build upon this work non-commercially, and license their derivative works on different terms, provided the original work is properly cited, appropriate credit is given, any changes made indicated, and the use is non-commercial. See: http://creativecommons.org/licenses/by-nc/4.0/.

ORCID iD

Alan G Fraser http://orcid.org/0000-0001-7083-6995

\section{REFERENCES}

1 Chalmers I. Underreporting research is scientific misconduct. JAMA 1990;263:1405-8.

2 World Medical Association. Declaration of Helsinki - ethical principles for medical research involving human subjects, 2018. Available: https://www.wma.net/policies-post/wma-declaration-ofhelsinki-ethical-principles-for-medical-research-involving-humansubjects/

3 Cheng A, Kessler D, Mackinnon R, et al. Reporting guidelines for health care simulation research: extensions to the CONSORT and STROBE statements. Simul Healthc 2016;11:238-48.

4 Husereau D, Drummond M, Petrou S, et al. Consolidated health economic evaluation reporting standards (cheers) statement. BMJ 2013;346:f1049.

5 Cronenwett JL, Avila-Tang E, Beck AW, et al. Use of data from the vascular quality initiative registry to support regulatory decisions yields a high return-on-investment. BMJ Surgery, Interventions, \& Health Technologies 2020.

6 Wimmer NJ, Robbins S, Ssemaganda $\mathrm{H}$, et al. Assessing the cost burden of United States FDA-mandated post-approval studies for medical devices. J Health Care Finance 2016;2016.

7 Fraser AG, Butchart EG, Szymański P, et al. The need for transparency of clinical evidence for medical devices in Europe. Lancet 2018;392:521-30.

8 Mohapatra A, Saadeddin Z, Bertges DJ, et al. Nationwide trends in drug-coated balloon and drug-eluting stent utilization in the femoropopliteal arteries. J Vasc Surg 2020;71:560-6.

9 International Medical Device Regulators Forum. Registry WG/N33 Final:2016. principles of international system of registries linked to other data sources and tools. Available: http://www.imdrf.org/docs/ imdrf/final/consultations/imdrf-cons-essential-principles -151124.pdf

10 McGettigan P, Alonso Olmo C, Plueschke K, et al. Patient Registries: An Underused Resource for Medicines Evaluation : Operational proposals for increasing the use of patient registries in regulatory assessments. Drug Saf 2019;42:1343-51.

11 Hoel AW, Faerber AE, Moore KO, et al. A pilot study for long-term outcome assessment after aortic aneurysm repair using Vascular 
Quality Initiative data matched to Medicare claims. J Vasc Surg 2017;66:751-9.

12 Johnston LE, Robinson WP, Tracci MC, et al. Vascular quality initiative and national surgical quality improvement program registries capture different populations and outcomes in open infrainguinal bypass. J Vasc Surg 2016;64:629-37.
13 The Brookings Institution. Strengthening patient care: building an effective national medical device surveillance system, 2015. Available: https://www.fda.gov/media/91224/download

14 Sutzko DC, Mani K, Behrendt C-A, et al. Big data in vascular surgery: registries, international collaboration and future directions. $J$ Intern Med 2020;288:51-61.

15 James S, Rao SV, Granger CB. Registry-based randomized clinical trials - a new clinical trial paradigm. Nat Rev Cardiol 2015;12:312-6. 